\title{
Masa en fosa iliaca derecha como forma de presentación de un hepatocarcinoma pediculado
}

\author{
J. Campos Franco, N. Mallo González, P. Barros Alcalde, G. Pazos González¹ y A. González Quintela \\ Servicios de Medicina Interna y ${ }^{\prime}$ Radiología. Complejo Hospitalario Universitario. Santiago de Compostela, A Coruña
}

\section{CASO CLÍNICO}

Mujer de 79 años sin antecedentes de interés que consultó por diarrea y síndrome general de un año de evolución. En la exploración física destacaba una masa palpable en fosa iliaca derecha que se confirmó en la radiografía simple de abdomen. Se realizó una tomografía computarizada abdominal revelando la presencia de una gran masa hepática (Fig. 1) con crecimiento exofítico hacia fosa iliaca derecha sugestiva de hepatocarcinoma. El páncreas, bazo, riñones, útero y ovarios eran normales. Las serologías de virus hepatotropos fueron negativas y los niveles séricos de alfafetoproteína se encontraban dentro de la normalidad. Tras una punción-aspiración con aguja fina de la lesión se obtuvo material cuyo estudio histológico demostró un hepatocarcinoma bien diferenciado. Descartada la resección quirúrgica por el tamaño tumoral y sospecha de invasión vascular se inició tratamiento con quimioembolización con buenos resultados. En el momento actual, tras seis meses de seguimiento, la paciente se encuentra asintomática.
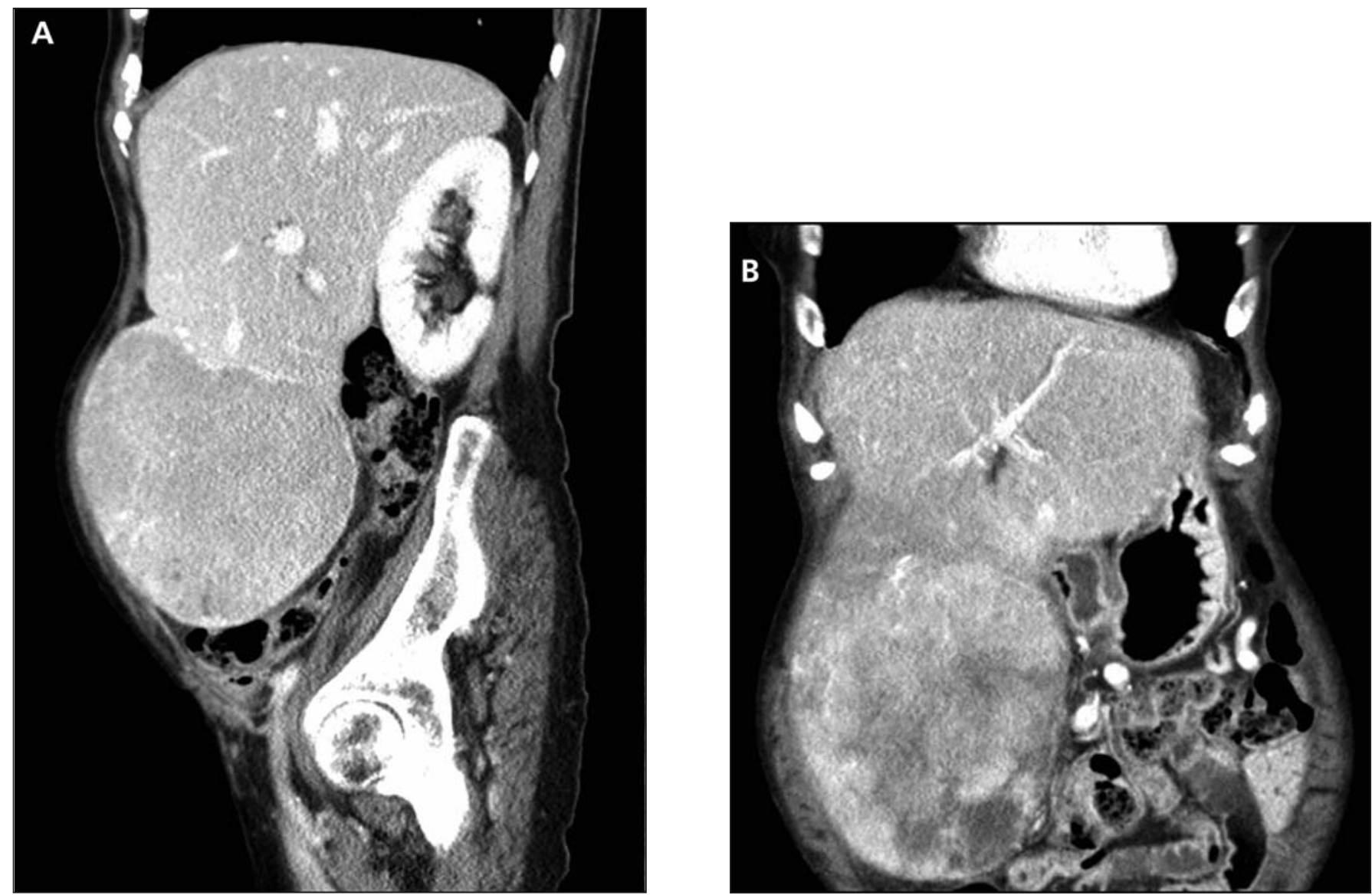

Fig. 1. Tomografía axial computarizada con contraste intravenoso y reformateados en plano sagital (A) y coronal (B). Gran masa hepática sólida de 13 $x 12 \mathrm{~cm}$ que se extiende desde el segmento IVb al VI, hipervascularizada en fase arterial, con cápsula bien delimitada y cicatriz central. 


\section{COMENTARIOS}

El hepatocarcinoma pediculado (o de crecimiento extrahepático) puede definirse como un hepatocarcinoma que protruye o sobresale de la superficie hepática (1). Puede presentarse como una masa unida al resto del parénquima por un auténtico pedículo o bien como una tumoración suspendida del borde inferior del hígado y que puede alcanzar la pelvis, como en el caso que presentamos $(1,2)$. Es una forma infrecuente de hepatocarcinoma caracterizada por su gran tamaño y por la presencia de cápsula. Aunque generalmente se ha considerado como una variante de peor pronóstico $(2,3)$, otros autores han propuesto que la cápsula y el pedículo disminuirían el riesgo de invasión vascular por lo que algunos pacientes podrían beneficiarse de una resección quirúrgica (4).

\section{BIBLIOGRAFÍA}

1. Tzouliadis L, Hulin SJ, Shaw I, Rees M. Image of the month -Pedunculated hepatocellular carcinoma. Arch Surg 2007; 142: 95-6.

2. Woodall CE, Scoggins CR, Loehle J, Ravindra KV, McMasters KM, Martin RC. Hepatic imaging characteristics predict overall survival in hepatocellular carcinoma. Ann Surg Oncol 2007; 14: 2824-30.

3. Horie Y, Shigoku A, Tanaka H, Tomie Y, Maeda N, Hoshino U, et al. Prognosis for pedunculated hepatocellular carcinoma. Oncology 1999; 57: 23-8.

4. Yeh CN, Lee WC, Jeng LB, Chen MF. Pedunculated hepatocellular carcinoma: clinicopathologic study of 18 surgically resected cases. World J Surg 2002; 26: 1133-8. 